\title{
"Lavo, Passo e Cozinho na sua Casa e pros seus Filhos, mas meu Filho que Mora Comigo Fica Largado na Favela": Reflexões sobre Suspeição e Precariedade nos Casos do "Cria de Favela" e da "Empregada Doméstica"
}

"I Wash, Iron Clothes and Cook at your Home and for yours Kids, but my Son Doesn't Live with Me, He Lives Alone in the Favela": Reflections on Suspicion and Precariousness in che Cases of the "Cria de Favela" and the "Maids"

Gabriel Borges da Silva

Universidade Estadual do Mato Grosso, Cuiabá, Mato Grosso, Brasil

Fábio Medina Gomes

Universidade Estadual do Mato Grosso, Cuiabá, Mato Grosso, Brasil

\section{RESUMO}

Neste artigo discutiremos precariedade e suspeição a partir de pesquisas distintas, uma realizada em lugares chamados de "favela" na Cidade do Rio de Janeiro e outra nas Varas do Trabalho da cidade de Niterói. A precariedade, para além de seu significado jurídico, será abordada como um dispositivo de poder na desigualação de sujeitos ao acesso a direitos e em relação às posições ocupadas na hierarquia social brasileira. Com a utilização de dados empíricos, bem como com a interlocução de teorias produzidas por outros pesquisadores a respeito do tema, discutiremos como esse processo de precarização permite e sedimenta justificações no espaço público e no convívio social para a demarcação de direitos desiguais, bem como para capitalizar um material simbólico que legitima uma atuação arbitrária do Estado frente às demandas sociais dos considerados precários.

Palavras-chave: Precariedade, Suspeição, Desigualdade. 


\section{ABSTRACT}

In this article, we will discuss precariousness and suspicion based on two different researches, the first carried out in places named "favela" in the city of Rio de Janeiro and the second in the Labor Court of the city of Niterói. Precariousness, in addition to its legal meaning, will be approached as a device of power in the inequality of citizens to access to rights and in relation to the positions occupied in the Brazilian social hierarchy. Based on empirical data, as well as the interlocution of theories produced by other researchers on the subject, we will discuss how this precarious process allows and consolidates justifications in the public space and in social life for the demarcation of unequal rights. It also capitalizes on symbolic material that legitimizes arbitrary action by the State in the face of the social demands of those considered precarious.

Keywords: Precariousness, Suspicion, Inequality.

\section{INTRODUÇÃo}

"A gente trabalha tanto! Tanto! Tanto! Se humilha em casa de madame e nossos filhos ficam aí largados nessas esquinas. Parecia que eu sentia, tava preocupada do Matheus andado com quem não devia. Mas é assim mesmo, ninguém dá nada de mão beijada pra gente, tinha que trabalhar e confiar na misericórdia divina. Mas não teve jeito, levaram meu filho, que ele esteja agora abrigado nas graças de Deus". Disse Nilcéia, doméstica, solteira, 33 anos, após seu filho Matheus, de 14 anos, ser morto em uma operação policial.

O presente artigo pretende debater a suspeição e a precarização como elementos centrais na lógica hierárquica na Região Metropolitana do Rio de Janeiro. Entendemos por suspeição uma determinada seleção entre as pessoas para se aplicar desigualmente a lei, que pode ser realizada pela polícia e por outras instituições brasileiras. ${ }^{1}$ Na presente pesquisa, são atores da polícia e do judiciário, bem como da sociedade civil na condição de empregadores quem agem com suspeição. Ao passo que compreendemos precarização como uma série de justificativas

1 Roberto Kant de Lima (1995) explica que a própria polícia não apenas investiga, mas tem a tarefa de vigiar, ou seja, ela não apenas apura fatos, mas vigia a população. Isso se realiza numa espécie de seleção para aplicar desigualmente a lei, dado que o tratamento dispensado depende do status da pessoa. Por meio de suposições relativas ao caráter do investigado, a polícia prevê essa ou aquela conduta delituosa. Desse modo, as hierarquias da sociedade brasileira se impõem sobre previsões políticas de respeito à igualdade. Em outras palavras, a própria aplicação da lei pela polícia depende do lugar desses sujeitos no estrato social. O que queremos apontar neste artigo é que não apenas a polícia tem agido dessa maneira, mas que a suspeição é uma característica muito capilarizada da nossa sociedade. 
que vêm permitindo a manutenção das hierarquias no espaço público brasileiro, legitimando a atuação desses atores de forma arbitrária, sobretudo frente às demandas sociais daqueles considerados precários. Aqui, a relação de juízes e policiais com empregadas domésticas, diaristas e seus filhos, seguirá como recorte, para refletir a relação entre suspeição e precarização, demonstradas na categoria "doméstica" e na figura do "cria". Abordaremos casos de mulheres que na condição de domésticas, ou seja, nem empregada doméstica nem diarista, como explicaremos, precisavam cuidar de seus filhos. A partir dos casos de Nilcéia, Agrado e Carmem, pretendemos explicitar a condição de desequilíbrio entre atores do Estado, pessoas mais aquinhoadas e aqueles considerados suspeitos, expressa no que chamamos de precariedade à brasileira.

É nesse sentido que as nossas etnografias demonstram meandros do processo de suspeição que sofrem os sujeitos tidos como "precários", nas suas relações com o Estado brasileiro. Esse movimento vem sendo observado em outras pesquisas que advêm de trabalho coletivo desenvolvido no âmbito do Laboratório de Estudos sobre Conflito, Cidadania e Segurança Pública da UFF, do qual fazemos parte. O que vem se verificando com essas pesquisas é que o Estado brasileiro age, arbitrariamente, distribuindo direitos de forma desigual. E essa repartição não favorece os sujeitos menos aquinhoados, mas, pelo contrário, favorece aqueles que mais têm acesso a recursos, por exemplo, criando-se regimes normativos desiguais. Fator que nos faz entender a relevância de observar e analisar esse fenômeno. Para tal, reunimos três casos que em nossos campos de pesquisa apresentaram como características comuns o trabalho doméstico e a maternidade.

A reunião dos dados apresentados neste artigo é resultante de um movimento que teve início em nossas pesquisas de doutoramento e mestrado ${ }^{2}$. Além de terem sido contemporâneas (2013-2019), tivemos a oportunidade de partilhar reuniões de pesquisa e nos apoiarmos no compartilhamento de ideias, assertivas e angústias durante a realização do trabalho de campo, além de leituras, interpretações e processo de escrita que envolvem a construção dos dados etnográficos. De fato, sem esses movimentos em comum não teríamos sido capazes de mobilizar o conjunto de dados necessários para enfrentar a questão aqui proposta. Produzimos um estudo do estado da arte a partir da relação de nossos referenciais de pesquisa que lidam com a questão da precariedade, bem como uma pesquisa em livros que produzem discursos sobre a questão da empregada doméstica. Além disso, utilizamo-nos dos nossos cadernos de campo para entender como a precariedade se constrói via a suspeição de atores que estavam presentes em nossos tra-

$2 \mathrm{O}$ primeiro autor do presente artigo se dedicou ao estudo dos lugares chamados "favelas" e das pessoas chamadas “crias". Já o segundo autor do presente artigo promoveu uma pesquisa de campo na Justiça do Trabalho, observando audiências que discutiam direitos trabalhistas de empregadas domésticas. 
balhos de campo, a doméstica e o cria. E percebemos que ambos encontram-se numa situação de precariedade.

Enquanto proposta, optamos por abordar situações que explicitavam o conflito entre perigo e reconhecimento de direitos a partir da relação entre suspeição e precariedade. O primeiro caso abordado será o caso de Nilcéia, de modo a observar como a relação entre vida e morte está disponível na relação entre a doméstica e suas crias, identidades precarizadas e que, portanto, padecem de reconhecimento de direitos individuais. Na sequência, traremos os casos de Agrado e Carmem, de modo a refletir como a ideia de perigo aparece na justificativa para a não contemplação de direitos trabalhistas de empregadas domésticas e diaristas perante a justiça do trabalho. Assim, pretendemos relacionar reflexões a respeito de tecnologias de produção de desigualdade. Tecnologias, inclusive já percebidas em outras pesquisas que dialogam com ambientes em que a dimensão da "tolerância" cobra pertinência e tem caráter estruturante ${ }^{3}$. É o caso, por exemplo, daquela conduzida por Pires (2010) ao tratar dos ambulantes da rede ferroviária carioca, descrevendo e analisando os dramas pelos quais se constroem a tolerância com pretensos desvios, dos mais diversos, ordenando as convivências entre diferentes percepções, moralidades e interesses no uso daquele equipamento público. Freixo (2013), por sua vez, ao tratar das desigualdades construídas a partir do processo de produção de verdades na Polícia Civil, mostra como sujeitos sociais podem ter suas identidades deterioradas a partir de processos conduzidos pelos inquéritos policiais que, no entanto, podem ser mitigados por objetos oficiosos que são objetos da discricionariedade dos agentes, em sede policial, precarizando a própria perspectiva normativa vigente. Em um outro exemplo de tais estudos, Silva (2014), ao tratar dos trabalhadores do Mercado Popular da Uruguaiana, no Centro da cidade do Rio de Janeiro, demonstra como o vazio normativo existente permite que os mais variados interesses operem em favor de que o regime de arbítrio resultante estabeleça barreiras aos fortes interesses imobiliários por uma área nobre da capital do estado do Rio de Janeiro. O que acaba, do ponto de vista dos camelôs, oferecendo mais garantias de permanência no local do que outros que, eventualmente, fossem universalizados. Todos estes trabalhos procuraram refletir sobre a noção de precariedade com base em seus campos empíricos, assim como Albernaz (2015), ao tratar de uma zona periférica de Niterói; Gomes (2015) ao estudar as empregadas domésticas, dádiva e mercados; Santos (2016) sobre a ordem pública e Garau (2017) ao tratar das Unidades de Polícia Pacificadora.

3 As tolerâncias expressam as relações de permissividade em que o Estado "tolera" determinadas práticas de sujeitos precarizados em troca da manutenção do controle sobre os sujeitos via práticas ilegais de seus agentes (SILVA, 2014). 
A socialização a partir dos dados de nossas pesquisas e a complementariedade de nossos cadernos de campo foram centrais na percepção de como, para além do Estado, a classe média ${ }^{4}$ brasileira é capaz de manipular a suspeição tanto no trato com as empregadas domésticas e diaristas como no trato com o "cria de favela". Como veremos no caso das audiências trabalhistas de Carmem e Agrado, que não foram reconhecidas como empregadas domésticas. Pelo contrário, na moralidade de suas patroas, que fora confirmada no judiciário, reconhecer esse direito era um perigo à "família brasileira", representada pela figura da "patroa". Entender a ideia de perigo permite a percepção deste que nos parece um dos principais elementos de suspeição. Fator que nos fez refletir a respeito do fato de muitos dos "crias de favela" serem também filhos de domésticas. A suspeição institui um pensamento de que algumas pessoas são perigosas enquanto outras foram postas em risco. Dessa forma, cria-se um discurso segundo o qual o cria, tal como a doméstica, colocam em perigo as camadas médias da sociedade.

Assim, devido às limitações dessa proposta, abordaremos essas três situações que se encontraram nesse enredo de mães que, por serem domésticas, deixavam seus filhos sozinhos para cuidar dos filhos de suas patroas. Afinal, percebemos que no cotidiano dos nossos interlocutores são eles mesmos que estão sob ameaça de perder rendimentos, direitos e a própria vida. Mesmo porque, como veremos, o Estado, na figura do judiciário e da polícia, não distribui esses bens (rendimentos, direitos e vida) de forma igualitária.

\section{AS PESQUISAS}

O trabalho de campo conduzido em área de favela foi realizado entre 2014 e 2019, via circulação e moradia em lugares chamados de "favela". Nas observações participantes desenvolvidas no contexto de imersão foram conduzidas conversas com os "crias do Timor Leste", uma esquina situada na chamada Favela do Vale. A preocupação era de acompanhar os movimentos, relações e justificações para a recorrente morte de jovens na região. Assim, a pesquisa abordou a produção de mortes. Nesse sentido, foi possível pôr em evidência justificações que

4 O conceito de classe média, para Jessé Souza (2018), vai além de uma questão econômica para simbolizar uma hierarquia moral e a justificação de privilégios.

5 Todos os nomes dos interlocutores foram mantidos em sigilo. Fizemos o mesmo com os bairros e demais referências que poderiam ser identificadas. 
eram utilizadas para as mortes, fortemente centradas nas moralidades acerca de quem pode morrer e quem pode matar. Em suma, as mortes são justificadas na conduta do indivíduo que morreu, como no caso da ideia de "deu mole", que mobiliza um sistema de crenças a respeito.

Enquanto isso, a partir do interesse nos assuntos sobre domesticidade, o trabalho de campo conduzido entre 2013 e 2015 buscou focalizar nas relações entre obrigações, direitos, dádivas e afetos entre o judiciário, trabalhadoras e empregadores domésticos. Naquele período, foram acompanhadas audiências trabalhistas e realizada uma sequência de entrevistas com profissionais do meio jurídico, bem como com empregadores e empregadas domésticas. O estrato aqui revelado dessa pesquisa procura compreender quais os discursos desses profissionais sobre a igualdade.

As duas pesquisas comunicam-se diretamente, tanto em suas principais questões quanto na construção dos dados, como referido, por vezes, partilhados entre os autores em reuniões e práticas de seu grupo de pesquisa. Inúmeros diálogos descritos nos dois trabalhos de campo se assemelham, sendo muito comum encontrar domésticas e crias em ambas pesquisas. Assim, os casos observados resultaram de reflexão conjunta, tanto na construção das narrativas, quanto nas preocupações éticas em relação à preservação da identidade e das histórias de vida dos interlocutores. Assumidos assim de forma conjunta, representam o constructo de experiências de mulheres que dialogamos em nossa pesquisa e que têm de enfrentar em seu dia a dia o nó na garganta de não ter direitos plenamente garantidos. Mas, além disso, elas demonstram uma classificação de perigosas para algumas pessoas na cidade do Rio de Janeiro e, por outro lado, legitima-se a distribuição desigual de uma série de bens. Essa prática, observada aqui via ação de juízes e policiais, será encarada nos casos de Nilcéia, Agrado e Carmem em seu conjunto de moralidades que justificam, por exemplo, a falta de acesso a recursos e a dificuldade de manutenção da própria vida.

Adiante abordaremos os campos de pesquisas do primeiro e do segundo autor. Frisa-se que, para as reflexões promovidas em comum, tomaremos os dados e as consequentes reflexões em conjunto para facilitar o entendimento do leitor, bem como para melhor explicitar o diálogo que resultou nas considerações a seguir.

\section{A QUESTÃO DO CRIA E $O$ CUIDADO DOS "MENINOS"}

A ideia que encabeça o título desse artigo surgiu a partir da fala de Nilcéia, que se 
apresentou como diarista, mas que trabalhava a semana inteira para a mesma família em casas diferentes. Uma nordestina que veio morar na cidade do Rio de Janeiro no Vale ${ }^{6}$ e ali gerou sua cria, Matheus. À época da pesquisa, o menino tinha 14 anos e "vivia na esquina do Timor Leste", como dizia Nilcéia. Ela contava os problemas que estava passando ao ir três vezes por semana na "casa dos meninos" e duas vezes por semana na "casa da patroa". Segundo Nilcéia, a "patroa era mais organizada e dava um monte de ajuda para ela", agora na casa dos "meninos" - que eram estudantes de medicina - ela sofria com a forma que era tratada. Chegou a me dizer que era obrigada "a limpar vômitos que ficavam de festas" e se via obrigada a cuidar mais dos "meninos" do que de seu filho "que só quer saber dessas esquinas". Quando ela foi reclamar com a patroa que era a mãe dos dois estudantes de medicina, recebeu um esculacho7:

Você é apenas uma diarista! Essa é a sua função e se não estiver satisfeita é só avisar que tem muita gente pobre querendo uma oportunidade de trabalhar que você não valoriza! Ainda mais sabendo que os 'meninos' precisam de tudo pronto para estudar... não para vagabundear por aí!

Nilcéia, informou que teve uma discussão com a patroa e retrucou a mesma dizendo: "lavo, passo e cozinho na sua casa e pros seus filhos, mas meu filho que mora comigo fica largado na favela”. Como retaliação à reclamação, Nilcéia falou que a patroa começou a atrasar os pagamentos das diárias que eram quinzenais. Ela chegou até a pedir dinheiro emprestado para ir trabalhar e, na casa dos estudantes, passou a ser ainda mais humilhada, ao passo que se via “como uma escrava". Porém afirmou que não podia reclamar, pois João, o pai do Matheus, que era pedreiro, morreu ainda novo. Nilcéia me contou que João bebia muito para compensar o desgaste de seu trabalho, pois pegava uma obra habitual na casa de uma "madame na Zona Sul do Rio de Janeiro" e vários outros serviços "por fora". Na época estavam construindo "a casinha" em um "terreninho" que tinham no Vale (próximo à esquina do Timor Leste) e Matheus era recém-nascido. Nilcéia podia cuidar de Matheus até o dia em que João "apagou" no trabalho. Segundo Nilcéia, colocaram a culpa na bebedeira, mas para ela seu marido morreu de

6 Vale é uma região que se encontra afastada do Centro da Cidade do Rio de Janeiro e que a partir dos anos 1990 ganhou a alcunha de "favela", perdendo a referência antiga ao bairro do Céu Azul e sendo referenciada pelos moradores de "Favela do Vale". O Vale é um lugar plano e sua geografia é composta de esquinas, ocupadas estrategicamente por seus moradores. A esquina do Timor Leste costuma reunir jovens, adultos que trabalham no próprio Vale e até crianças. Alguns dos jovens têm envolvimento com o tráfico, mas o que os mantém naquela esquina em específico são relações de amizade, que atribuem ao fato de terem nascido e crescido ali naquele local. Portanto, se representam como "crias de favela".

7 Segundo Pires (2010), o "esculacho", diferente da "esculhambação", que é uma ação de insulto assumida como possível, vai para além do limite do possível ao ponto que ele repercute uma reação necessária. 
tanto trabalhar. Teve um "mal súbito", segundo os médicos, e não retornou a vida. Desde então Nilcéia passou a levar Matheus para as "casas de família" em que trabalhava. Com o tempo e o crescimento do seu filho, esse movimento se tornava mais complicado. No começo, "ele ainda me ajudava, mas depois acabava dando muito trabalho e comecei a perder serviços por isso". Então, conforme a necessidade de trabalhar de Nilcéia, seu filho seguia as etapas de crescimento de um cria do Vale, na esquina do Timor Leste.

Há algum tempo, quando Nilcéia achava que seu filho frequentava a escola, ele afirmava que ia somente nas aulas quando queria. Sua alegria mesmo era passar o dia com os outros "crias da sua quebrada". O cria é aquele sujeito que constrói sua identidade a partir de valores e moralidades que atribuem sua existência a uma circulação local. Onde "brotar, nascer, crescer e morrer" são etapas de relações que se constituem entre jovens de locais chamados de "favela". Ser cria, no contexto que foi observado no Vale, representava ter nascido e crescido ali, quando esse crescer representava a partilha de uma série de experiências e aventuras que englobavam um universo com bandidos, policiais, pessoas da igreja, trabalhadores, sujeitos morais em constante relação com a morte. Uma das coisas que remete ao cria é que ele está fadado a morrer, seja literalmente ou socialmente.

Segundo os entrevistados e as situações observadas, todos conheciam alguém dali que já fora morto. Seja em confronto com a polícia, disputas no comando do tráfico ou por acesso a tratamento de saúde precário, como desnutrição e tuberculose. No entanto, o que foi identificado na pesquisa como uma produção sistemática de mortes, repercutia nas ações dos próprios crias que haviam morrido. Ou seja, as moralidades partilhadas compunham justificações sobre a atitude do cria, que destacava o desencadeamento de sua morte. O que poderia acontecer por meio de uma fofoca, um conflito ou pelo fato de estar no lugar errado, na hora errada. Esta última questão foi a que justificou a morte de Matheus e pareceu anunciada na preocupação de Nilcéia ao discutir com sua patroa.

Alguns meses depois da conversa com a Nilcéia, a história de Matheus fora mais bem acompanhada em constantes visitas à esquina do Timor Leste. Ele era muito perspicaz em relação à "vida do crime" e aos "rolês" que gostava de fazer. Como ele mesmo relatou, ir ao colégio não era o que gostava de fazer e aproveitava a ausência da mãe para faltar aula. Às vezes, ficava "na atividade" do Patolino, jovem de 19 anos que exercia uma função no tráfico local. Certo dia, ele deixou o rádio transmissor com Patolino que seguiu com outros rapazes para se esconder do "caverão" ${ }^{8 "}$ que circulava no Vale naquele momento. Esses jovens, que habitual-

8 Veículo blindado da Polícia Militar do Rio de Janeiro, que se assemelha a um tanque de guerra e é utilizado em 
mente trabalhavam para o tráfico de drogas, foram para seus esconderijos. Segundo os outros "crias" que ficavam no Timor Leste e não trabalhavam para o tráfico, o Matheus quis ficar num bar com um fliperama. Os outros também resolveram sair dali com receio da operação policial. Quando Matheus saiu do fliperama, foi alvejado com um tiro na cabeça e outro no braço por policiais que andavam a pé. Segundo relatos, ninguém havia visto esses policiais até o momento dos disparos. Logo em seguida, os policiais passaram na frente do bar apontando suas armas, passaram por Matheus e foram resgatados pelo "caverão" que vinha pela outra rua. Dali seguiram em diante com a operação, sem sequer tomar qualquer atitude sobre o corpo de Matheus.

Em conversa com Nilcéia, após a morte de Matheus, ela estava arrasada e impultava a morte de seu filho ao fato de não poder estar com ele. Segundo ela, deveria ter prestado atenção e não ter deixado sua "cria se misturar" com os outros rapazes do Timor Leste. Segundo os rapazes, a morte do Matheus se deu pelo fato dele ter "dado mole" de não sair na hora certa daquele local, pois é sabido que "a polícia quando vem atira para matar".

Nós entendemos a morte do cria e o trabalho doméstico remunerado como elementos constitutivos de dois mercados distintos, ambos mantidos pela mesma lógica, já que o Estado e a sociedade estabeleceram um conjunto de relações de trocas e circulação de valores morais. As mortes do cria nos lugares chamados de favela não são reclamadas e, por conseguinte, não informam preocupação do sistema de justiça criminal. Os óbitos são responsabilidade de quem morreu, como na ideia de "deu mole", que conecta o infortúnio da morte a ações pretéritas de quem morreu (SILVA, 2019, p. 154). Em outras palavras, existem motivações e até necessidades de se produzir tais mortes, contudo, instituições como a polícia ou o judiciário não desejam assumir essa responsabilidade.

De fato, o que se confirmou fora a previsão de Nilcéia. Aliás, para que os filhos da patroa pudessem estudar, ela deixava o filho dela à mercê de uma série de lógicas de violência norteadas por uma gestão estatal, que legitima a morte daqueles que oferecem perigo à chamada segurança pública ou à "família" brasileira. Neste caso, aquela que se remete a classes mais abastadas que, como no caso, não podem correr o perigo de estar sem uma doméstica para que tenham tranquilidade de estudar. Ao passo que os perigos encarados pelas trabalhadoras nessas condições parecem não fazer parte das preocupações do Estado, como veremos a seguir.

incursões policiais em lugares chamados de "favela". 


\section{O PERIGO E A DOMÉSTICA}

Assim como Nilcéia, Carmen era outro exemplo de uma doméstica que esteva sempre em perigo, dado que nunca sabia se era empregada ou diarista. Ela sempre esteve em perigo, podendo ser dispensada a qualquer tempo sem que ninguém lhe pagasse aquilo que ela considerava devido por seu trabalho. Carmen foi contratada para ser cuidadora de criança, depois passou também a realizar faxinas e lavar a louça da sua patroa. Segundo Carmem, apesar disso ter aumentado seu tempo de trabalho, continuou recebendo sempre um salário mínimo mensal. Contou as várias vezes em que foi acusada de furtos, mas deixou claro que seu problema principal era não dar atenção a seu próprio filho, porque só podia ir para sua casa uma vez por semana. Enquanto seu filho ficava num quarto com mais umas quinze crianças sendo cuidado por uma única mulher em Assis, lugar chamado de "favela" em que seu filho crescia.

João ainda estava na primeira etapa desse movimento dos crias e, dado o exemplo de Matheus e o destino de diversos outros jovens nesse contexto, a preocupação de Carmem era verídica. Como ela mesmo disse enquanto a filha da patroa tinha ela à disposição para catar até seus piolhos, João só podia vê-la uma vez na semana. Sendo assim, a cria de Carmem crescia na confiança dos cuidados de alguém que lidava com mais quatorze crianças à mercê de conflitos e de ações como a que culminou na morte de Matheus. E, como podemos perceber, caso algo dê errado, a responsabilidade de a empregada doméstica ter sido demitida ou a culpa da morte do cria não são do Estado ou da sociedade, mas imputam-se a supostos erros cometidos por esses sujeitos. A responsabilidade de ser precário não é de ninguém mais do que dessas pessoas, como se não houvesse outros ganhando capital econômico e social (o Estado, a polícia, a família de classe média) com esses empobrecimentos e mortes.

Além disso, todo esse mecanismo mantém o estereótipo destes sujeitos como pessoas perigosas. E realiza isso por meio de uma moralidade envolvendo afetos, desconfiança, cuidado, culpa ou amor. Existe, assim, um conjunto de sentimentos morais tornando nebulosa a percepção de que estão precários devido à forma como as instituições lidam com suas vidas. A conversa com Carmem foi única e se deu nos corredores da Justiça do Trabalho do Rio de Janeiro. Ela tentava comprovar juridicamente seu vínculo empregatício, porém sua patroa não compareceu novamente à audiência e Carmem era obrigada a continuar na mesma situação de perigo.

As práticas observadas demonstram que tal relação disponibiliza um tratamento que, para além das barreiras do legal e ilegal, expressa uma ação típica do Estado condizente com 
o status do destinatário da tutela jurídica. Nilcéia, Carmen e mais tantas interlocutoras deixam evidente a relação entre suspeição e precariedade, nos termos que temos usado até agora. No caso das domésticas, a suspeição que se constrói sobre as trabalhadoras, informa uma preocupação do judiciário com a proteção da "família brasileira" de classe média. Conforme a patroa de Nilcéia que justificava todo esculacho sofrido pela mesma, na necessidade de estudo de seus filhos que cursavam faculdade. Ou, como no caso da patroa de Carmem que se esquivava da justiça e a mantinha a uma semana distante de João via acusações e ameaças. Afinal, quem cataria os piolhos da cabeça da filha da patroa da Carmem senão ela mesma. Aliás, a ameaça de dispensa, a partir do fato de ser uma mera diarista, não é incomum e vai ser observada também no caso de Agrado.

A pesquisa feita na Justiça do Trabalho partiu principalmente de acompanhamento de audiências envolvendo trabalhadoras domésticas e de conversas informais com juízes, empregadas, empregadoras e outros sujeitos. A grande maioria desses processos terminava em acordos e existiam muitas falas sobre as moralidades envolvendo essa atividade. Os juízes falavam que não podiam realizar um acordo muito oneroso para as famílias empregadoras. Queriam dizer com isso que não podiam gerar perigo para o bem-estar daquela família ${ }^{9}$, sem levar em conta o perigo da trabalhadora em receber um valor menor do que lhe era de direito. Os acordos representavam uma fórmula de cálculo muito complexa que era estabelecida por negociações em audiências.

A audiência de Agrado ocorreu em 2014 e serve para exemplificar esses discursos jurídicos sobre os acordos. Ela estava postulando em juízo em face de Huma. No início da audiência, tão logo elas se sentaram, o juiz perguntou para os advogados: “Tem acordo, doutores?” Ambos afirmaram que, por enquanto, não havia um acordo. O juiz insistiu, mas eles não pretendiam acordar, não naquele momento. Ele pretendeu ouvir, então, a testemunha de defesa, Manuela. Ela afirmou o desejo da Agrado sair do trabalho para cuidar de seu filho.

O juiz questionou se os advogados teriam algo mais a perguntar para a testemunha Manuela. Ambos disseram que não. Ele fez uma proposta de acordo. Olhou para Huma e seu advogado falando: "Com essa testemunha, que não sabe quando trabalhou, acho que podemos ver um acordo de R\$ 1.200,00”. Todos concordaram, menos Agrado. Ela disse um não tímido. O juiz olhou para o advogado, dizendo: "Dá uma orientação para sua cliente, porque você é mais instruído que ela". Ele deu "sua orientação" e Agrado aceitou o acordo. Em seguida discutiram

9 É bem verdade que diziam temer também por não ser um valor muito alto e as empregadas domésticas não receberem nunca. 
quando e como Huma pagaria.

Para aquele juiz, o advogado de Agrado deveria explicar a ela que era melhor fazer o acordo. Como se a intervenção do advogado fosse uma forma de alcançar a concordância de Agrado. Existe, nesse sentido, uma interpretação do papel do advogado na qual ele deve tutelar a trabalhadora doméstica. Relembrando Simoni Lahud Guedes (1997), para quem, no Brasil, as classes abastadas se representavam como pessoas com o dever pedagógico de orientar as classes populares. Nesse episódio, segundo pensamento de juízes e advogados, Agrado deveria aceitar o acordo. Afinal, significaria uma forma de obter dinheiro mais fácil para os advogados; uma maneira do juiz se adequar às metas do número de processos acordados do próprio sistema de justiça e; logicamente, uma forma de Huma não pagar um valor ainda maior em caso de uma sentença judicial. Todos pareciam anuir, menos Agrado. A trabalhadora doméstica não concordou em acordar, tornando-se um perigo. Ou pelo menos lida pelos demais interlocutores como um perigo, dado que bastou uma conversa com o seu advogado "instruído" para que ela anuísse.

A audiência descrita acima era mais uma das muitas acompanhadas entre 2013 e 2015, em que a trabalhadora doméstica requeria o vínculo empregatício. Os profissionais jurídicos reputavam o acordo como uma boa forma de administrar esse conflito. Os advogados diziam que, embora os valores dos acordos fossem pequenos, eles receberiam esse valor rapidamente. Caso não houvesse acordo, a sentença poderia sofrer um recurso. Isso criaria uma demora no processo de meses ou anos. Já os juízes recebiam várias cobranças da própria Justiça do Trabalho para que realizassem mais acordos. Contudo, poucas trabalhadoras domésticas se empolgavam com os acordos, dado que sempre esperavam mais. Como o trabalho das empregadas domésticas era realizado na residência dos patrões, não existia controle de ponto marcando quantas vezes por semana elas trabalhavam, e isso era primordial para que o juiz decidisse se ela era uma empregada doméstica ou uma diarista, o acordo parecia facilitar o trabalho dos juízes e advogados. Verifica-se que no campo do direito, tanto as legislações ${ }^{10}$ como os julgamentos sobre o trabalho doméstico remunerado criaram uma situação em que as famílias de classe média não são obrigadas a pagar o mesmo ordenado que pagariam caso se tratasse de outra categoria profissional. Isso tudo, legitima a uma desigualdade de direitos, que legalmente precarizam o como viver das domésticas e consequentemente muitas das vezes o como e o até quando viver de suas crias.

Essa polêmica de reconhecer o vínculo empregatício se dá porque existe uma diferenciação no tratamento legal dispensado às empregadas domésticas. Essas legislações que regeram

10 Quando não equipara a empregada doméstica em direitos aos demais trabalhadores com vínculo empregatício. 
e regem o trabalho doméstico remunerado são muito complexas, contudo, é certo que a lei e a própria jurisprudência da Justiça do Trabalho têm criado regras diferenciadas para a comprovação do vínculo de emprego doméstico (GOMES, 2015).

Nesse sentido, a sociedade brasileira, no exercício de suas relações conflituosas, criou três categorias distintas: a "diarista", a "empregada doméstica" e a "doméstica". A primeira, a "diarista", não tem vínculo de emprego, tendo poucos direitos. É profissional autônoma. A “empregada doméstica” tem o vínculo de emprego, com mais direitos. Podendo ter ou não a sua formalização do contrato de emprego, isto é, sua carteira assinada pelo empregador. A última categoria, segundo os interlocutores, é simplesmente "doméstica", ela identifica tanto a diarista quanto a empregada doméstica. É uma forma de se referir ao trabalho doméstico remunerado de qualquer espécie, expressão muito comum entre as próprias trabalhadoras.

Embora essas diferenciações apresentem alguma certeza, na prática, apenas há dúvidas, devido à dificuldade de comprovação do vínculo empregatício. O caso de Nilcéia é um exemplo dessa confusão, ao passo que mesmo trabalhando a semana praticamente toda para a mesma família, era tratada como diarista. Conforme podemos perceber também no caso de Carmem, que ia para casa apenas uma vez na semana e de Agrado, que nem a "tutela judicial" garantiu o reconhecimento de seu vínculo como empregada doméstica. Além de criar essas categorias, o direito criou a situação especial. Percebemos que muitos dos advogados das trabalhadoras domésticas receavam não conseguir provar o vínculo de emprego. Enquanto, por sua vez, os advogados dos empregadores tinham medo de que o mesmo fosse provado. Todos os acordos observados surgiram como soluções intermediárias para que esse problema não fosse enfrentado. O acordo tem o papel de terminar esse debate, sem, no entanto, fornecer uma resposta. Assim, a Agrado saiu da audiência sem saber se, para o direito e para o juiz, ela foi empregada doméstica ou diarista. A partir de agora estaria com seu filho, ao menos enquanto durassem os $\mathrm{R} \$ 1.200,00$ que recebeu no acordo.

\section{OS DISCURSOS JURÍDICOS SOBRE TRABALHADORAS DOMÉSTICAS REMUNERADAS}

Assinale-se o contraste da cidadania brasileira, marcada pela naturalização da desigualdade, com o ideário da cidadania em outras sociedades. O ideário dos indivíduos iguais numa sociedade liberal está contido nas ideias de cidadania (CARVALHO, 2007). Contudo, entre nós, os direitos não eram conquistas, mas outorga da coroa, com o objetivo de promover a compen- 
sação da desigualdade jurídica naturalizada. Ao invés de extirpar as desigualdades sociais, o nosso modelo de cidadania procura acomodar as desigualdades (MENDES, 2008).

Essa mesma questão ficou também óbvia ao ler alguns discursos emitidos pelo judiciário trabalhista, para além do já apontado daqueles sobre os acordos. Os discursos que analisaremos em seguida revelam práticas judiciais dos juízes. Descrevemos alguns discursos não oficiais do judiciário. Um é de um livro de um autor muito citado pelos juízes nas entrevistas. O outro é de livros antigos voltados ao ensino de direito do trabalho.

Um dos autores muito citado pelos juízes que foram interlocutores é desembargador aposentado e autor de um livro denominado "Manual de Contrato de Trabalho Doméstico: direitos, deveres e garantias dos empregados e dos empregadores domésticos"11. Foi editado pela Editora Forense, tradicional entre os juristas. Ao final do livro, o autor respondeu algumas perguntas práticas. Cada bloco de perguntas e respostas desse livro recebeu um nome, segundo o tema abordado. Dentro dessas divisões havia uma que me chamou atenção, era denominada "Crime". Nesse item existiam três perguntas. A primeira era: "Que garantias tem o patrão de que a empregada não furtará coisa de sua residência?” Em seguida ele indagou: "Quem garante que o empregado não pertence a uma quadrilha de sequestradores?" Na primeira pergunta, sobre os possíveis furtos das empregadas domésticas, o autor mencionou casos de falsas empregadas domésticas. Pessoas que, premeditadamente, se passam por domésticas para realizar furtos. Para evitar tal perigo, uma das soluções seria a contratação de empregadas domésticas por agências de emprego, diz. A segunda solução seria o cuidado na hora da contratação. Por fim, ressalte-se uma assertiva do autor que merece destaque,

Afastá-lo completamente é muito difícil, porque, mesmo na época em que as empregadas domésticas eram cadastradas e tiravam carteira profissional na Delegacia de Polícia, isto ocorria; os falsos domésticos sempre existiam (SANTOS, 2003, p. 59).

Respondendo à questão sobre "quadrilha de sequestradores", o autor voltou a mencionar a necessidade de cuidados na contratação. Remete ao tempo em que as empregadas domésticas deveriam ter seu registro realizado na polícia, uma cena comum no final do Século XIX, como explica Lorena Telles (2013). Para Santos (2003) seria imprescindível uma pesquisa sobre os antigos empregadores dos pretendentes ao cargo. Havia uma mensagem clara nessas respostas, se o empregador tivesse dúvida sobre a idoneidade do empregado, não devia contratá-lo. Dado

11 Não encontramos uma edição mais recente, com as mudanças da nova Emenda Constitucional. 
que, nessas circunstâncias as classes média e alta sofreriam risco, perigo. Segundo ele,

Tal como dissemos na resposta anterior, esse risco é inerente a quem emprega pessoas e ele aumenta à medida que não forem tomados cuidados na contratação do empregado doméstico. Além disso, a posição social das famílias - as classes média, media-alta e alta são segmentos sociais de risco expõe seus membros à ação destes criminosos (SANTOS, 2003, p. 60).

No entanto, não é de hoje que o discurso jurídico entende as empregadas domésticas como pessoas perigosas. Na verdade, a ideia de perigo sempre esteve presente nos livros de direito. Ainda no final da década de 1950, José de Segadas Viana et al. (1957), alegou que era dispensável normatização quanto ao emprego doméstico, posto que havia:

amizade entre a empregada doméstica e a família, permitindo que a vida não seja rude e que o repouso semanal e o descanso seja mais ou menos respeitado. Isso somado ao acréscimo ao salário feito pelas prestações como residência, vestiário de trabalho e alimentação de maneira a permitir que suas condições de vida não sejam miseráveis (VIANA, 1957, p. 182).

Mozart Victor Russomano (1984), outro conhecido autor, décadas após a publicação da Consolidação das Leis do Trabalho, afirmou que:

Em substância, a relação de emprego residencial é a mesma relação de todos os outros contratos de trabalho. Mas, o doméstico vive na intimidade da família e, por esse motivo, o legislador considerou de bom aviso excluí-los, ratione personae (verbete), do raio protecionista da Consolidação.

Essa atitude é injusta. Todos conhecemos os abusos dos empregados domésticos, sua irresponsabilidade e os riscos do empregador, obrigado a aceitá-los sem conhecê-los, dentro de sua própria casa, no convívio de todos. Mas, o que não nos parece humano e razoável é, em face disso, excluí-los da proteção mínima assegurada a todos os que trabalham.

Se corrermos os olhos pela Consolidação, não encontraremos nela um só dispositivo que dê quaisquer direitos aos domésticos.

A regulamentação do serviço doméstico é difícil, porque o legislador deverá conciliar direitos, até hoje negados, do trabalhador doméstico com seus deveres de zelo, fidelidade e correspondência à confiança que neles se deposita. Esses obstáculos poderão ser superados se se resolver caminhar examinando, antes, o terreno e se não quisermos, de relance e abruptamente, como quase sempre acontece no Brasil, fazer tudo completo e perfeito, embora até então nada tivéssemos feito (RUSSOMANO, 1984, p. 157).

Essa peculiar compreensão sobre o perigo foi muito marcante em todos os discursos sobre igualdade proferidos tanto pelos profissionais do meio jurídico quanto por empregadores domésticos. Segundo podemos compreender desses discursos, a empregada doméstica e sua 
família eram tidos como perigosos, enquanto a família empregadora de classe média estaria sempre passando por algum risco, na concepção dessas pessoas. Como nos casos aqui descritos. Contudo, quem poderia ser taxada de diarista e não ter onde reclamar seus direitos, quem sempre recebia um valor compreendido como pequeno por algum acordo, quem tinha menos direitos se comparado aos outros empregados, era a trabalhadora doméstica, nunca a família dos empregadores.

Curiosamente, os discursos desses interlocutores sobre essas trabalhadoras também ignoravam aquilo que foi pesquisado por uma série de autoras e autores das ciências sociais brasileiras. Como Heleieth Saffioti (1978), apontando sobre a dinâmica do mercado de trabalho doméstico que aumenta em tempos de crise e retrai-se com a expansão econômica, dado que é um setor preterido pelas próprias empregadas que, quando podem, se dedicam a outras profissões. Como Fernando Cordeiro Barbosa (2010) quem debateu sobre a confusão entre trabalho e moradia. Ou mesmo como Maria Claudia Coelho e Claudia Rezende (2013), que estudaram a troca de presentes entre patroas e empregadas. Mesmo a pesquisa de Roberto Damatta (1986) vai relembrar a empregada doméstica como alguém que deve fazer uma das únicas coisas proibidas em casa para os demais, o trabalho. Interessante refletir que todos esses discursos sobre gênero, raça e desigualdade social não foram comentados nesse livro jurídico e nem nas falas dos profissionais desse mesmo campo. O que, a nosso ver, confirma a lógica da precariedade à brasileira imposta às empregadas domésticas e que, como vimos, impacta também na vida de seus filhos e família.

\section{A SUSPEIÇÃO, A PRECARIEDADE E 0 PERIGO}

Os dados apresentados até agora apontam para uma série de análises teóricas importantes nas duas pesquisas, possuindo uma forte identidade entre si. A "favela" não é somente um lugar e não representa uma ausência de direitos, porém explicita que há um regime jurídico desigual para diferentes sujeitos em nossa sociedade onde o morrer se expressa em formas de viver.

Como no caso da Nilcéia, que teve seu filho de 14 anos morto em uma operação policial. O Vale, um lugar classificado como "favela", produz valores morais, sujeitos e formas de existir, bem como de resistência e persistência de experiências do viver e do sobreviver. Como as que serão encaradas por João, filho de Carmem. Afinal, "a favela" é uma classificação que se deve utilizar com cuidado, uma vez que pode ampliar uma percepção equivocada de que o 
espaço de relação de esbulho com a propriedade produz regimes morais universais, quando a experiência irá demonstrar distintas formas desse exercício de resistência. Isso, pois "a favela" enquanto universalidade permite o "esculacho" (PIRES, 2010), como trato característico do poder do Estado, que é distinto para cada uma das camadas sociais repercutindo em direitos relativos.

Não é por acaso que, enquanto nomenclatura, "a favela" serve como justificativa moral para aplicação de um direito desigual, que concerne à produção sistemática de mortes dentre outros esculachos. Produção que se aplica via um sistema de suspeição que coloca o "cria de favela" como um sujeito que pode ou está fadado ao morrer caso "dê algum mole" em relação a todos os perigos, que na verdade esses jovens nascidos e criados em lugares chamados de "favela" estão à mercê em suas trajetórias de vida. Por outro lado, olhamos com estranhamento o fazer do jurista em uma audiência trabalhista que visa cumprir o acordo ou encontrar uma solução "terminativa" para os conflitos a partir de um sistema hierárquico de normas. Isso nos demonstrou que não há uma demarcação espacial sobre essa atitude do Estado, mas a produção de uma suspeição que recai sobre sujeitos considerados perigosos em relação a valores disponíveis para as classes mais abastadas. Inclusive, essa suspeição é ensinada e reiterada em aulas, livros e discursos como demonstrado em relação à empregada doméstica.

Assim, a tutela da família e dos bens familiares virava parte significativa das moralidades disponíveis para o encontro de uma solução "terminativa" para uma audiência trabalhista que envolvia empregadas domésticas. Ou seja, a classificação dada ao trabalho doméstico poderia implicar na ausência ou na parcialidade de reconhecimento de direitos trabalhistas. Em que sua salvaguarda estava relacionada ao perigo de se equipar direitos iguais para essa classe trabalhadora. Talvez isso explique que no desenrolar das pesquisas pudemos perceber que muitas empregadas domésticas viviam em lugares chamados de "favela", por ser na cidade do Rio de Janeiro, um lugar possível de moradia. Ao passo que muitos crias que moravam no Vale e frequentavam a esquina do Timor Leste eram filhos de empregadas domésticas. E, como no caso de Matheus, ficavam a maior parte do dia nas esquinas à mercê de ações diversas, inclusive do Estado, que poderiam justificar sua morte.

Para o presente artigo, interessou-nos pensar como o direito criou a ideia de que essas mulheres e suas crias são perigosas. Assim, trouxemos diversos estratos do trabalho de campo, privilegiando falas dos interlocutores e revistas e livros de autoria de diversos profissionais do campo jurídico. Esses mesmos discursos colocam as famílias dos empregadores domésticos como pessoas que vivem ameaçadas por suas empregadas. De certo modo, essa relação está descrita em textos clássicos do pensamento social brasileiro, notadamente em Sobrados e Mu- 
cambos (FREYRE, 1990), para quem uma forma específica de relação entre as classes e raças funda a ideia de homem brasileiro. A relação do senhor rural na cidade é de profundo repúdio da rua, uma vez que na rua estaria o povo. Essa figura constantemente do espaço público como um perigo estava profundamente relacionada ao histórico da escravidão. Nas palavras de Jessé Souza (2000),

Desse modo, a urbanização representou uma piora nas condições de vida dos negros livres e de muitos mestiços pobres das cidades. O nível de vida baixou, a comida ficou pior e a casa também. Seu abandono os fez então perigosos, criminosos, capoeiras etc. Os sobrados senhoris, também nenhuma obra-prima em termos de condições de moradia, por serem escuras e anti-higiênicas, tornaram-se com o tempo prisões defensivas do perigo da rua, dos moleques, dos capoeiras etc. (p. 88).

A ideia da precariedade não é o lugar do incerto e frágil, mas potencializa o regime normativo que incrusta nas vidas dos sujeitos que estão em uma situação de pedintes da tutela do Estado e distribui direito e acessos de acordo com a forma que são ou não avalizados pelas estruturas de poder. Ou seja, vivem por meio de dinâmicas de poder arbitrárias, com saberes locais e que colocam a experiência de viver na cidade numa "[...] incerteza de sua permanência no espaço e no tempo" (PIRES, 2016, p. 323). Conforme nossas pesquisas e o próprio estado da arte apontam, são ações de poder que pela desconstrução de sujeitos e o movimento das interações possibilitariam a construção de tecnologias e dispositivos visando efetivação de poder (FOUCAULT, 1997).

Esses vários interlocutores das nossas pesquisas nos ensinam muito sobre a relação de suspeição entre o Estado brasileiro e os particulares, como têm apontado diversos autores já há diversas décadas, notadamente Roberto DaMatta (1979; 1986) e Roberto Kant de Lima (1995). Primeiramente, podemos perceber que são sujeitos que receberam direitos desigualmente, se comparados aos outros indivíduos. Assim, o cria na sua relação com a polícia ou a doméstica com a Justiça do Trabalho. Tudo isso aponta para indivíduos com direitos diferentes, ou seja, em direitos desiguais para pessoas em condições jurídicas semelhantes.

Desse modo, a ideia de precariedade pode ser debatida pensando no cria e na doméstica. Esse conceito atravessa autores da sociologia do trabalho, como Pierre Bordieau (1998), Manuel Castells (2002) e Ricardo Antunes (2015). Esses autores retrataram situações onde o empregado se submete cada vez mais ao capital, num crescente de exploração sem limites. Essa ideia de precariedade não deve ser confundida com aquela categoria "precariedade" que tem sido objeto de problematização de estudos realizados no âmbito do Laboratório de Estudos sobre Conflitos, Cidadania e Segurança Pública. 
Por exemplo, Pires $(2017 ; 2017)$ e Silva $(2014,2019)$ têm se dedicado a pensar sobre as consequências da adoção de regras jurídicas desiguais para pessoas em realidades semelhantes. Silva (2014) ao observar a gestão pública para o cidadão classificado como camelô verificou que a mesma se desenvolve a partir de uma distribuição desigual de direitos marcada na lei que repercute no imaginário social e é reproduzida pelas instituições que se percebem como jurídicas. Justamente aquilo que podemos perceber da relação estatal com essas duas figuras, o cria e a doméstica.

Pires (2017), por exemplo, reflete como a categoria "precariedade" migra do direito patrimonial para o direito administrativo, parecendo mover-se do direito das coisas para as representações dos indivíduos. Segundo ele, a qualidade do precário emerge no contexto em que uma pessoa pede a devolução de uma propriedade cedida para o usufruto de uma pessoa e esta última se nega a fazê-lo. O autor sugere que neste âmbito se verifica a quebra da confiança até então existente naquela relação, fazendo com que o dono da propriedade se volte para o Estado para que este atue de forma coercitiva para reaver o que é seu por direito.

O que é criativo na sugestão de Pires (2017), quando pensa a maneira como o direito administrativo conjuga a noção de precariedade, é que o Estado define que certos atores sociais não são passíveis de estabelecer para com ele um contrato que, por exemplo, resulte na ocupação do espaço público. É o caso dos comerciantes ambulantes, como ele analisa. Isso só se verifica com esse mesmo Estado, no caso o poder executivo municipal da cidade do Rio de Janeiro, delimitando a concessão de uso em caráter precário e, logo, passível de rompimento unilateral de acordo com seu estrito desejo. O ponto do autor é que nestas situações se proclama que o desenvolvimento humano, social e econômico desses sujeitos não é passível de gerar direitos, havendo uma suspeição prévia de que esse ator irá romper qualquer espécie de contrato, por menos duradouro que seja. E que, portanto, durante o usufruto da concessão, ele não tem garantias quanto a sua integridade moral e física. Por isso mesmo o direito administrativo, por exemplo, refere que a atividade ambulante é exercida "por sua conta e risco" (Pires, 2010).

E para além, como analisado na proposta do presente artigo, esses processos de suspeição fazem crias e domésticas acreditarem que sua condição enquanto precárias é permanente, da mesma forma que apontou Judith Butler (2006) quando do seu debate sobre precariedade. Essa autora, ao estudar sujeitos como os imigrantes muçulmanos nos Estados Unidos, vai afirmar um elemento importante que também percebemos em nossos trabalhos de campo: esses sujeitos acreditam na precariedade como uma condição fixa e naturalizada do seu pertencimento no mundo e não como uma situação que pode ser vencida. As domésticas e suas crias de alguma forma assimilam a precariedade e a impossibilidade de poder sair dessa situação. 


\section{CONSIDERAÇÕES FINAIS}

Desse modo, com movimento aqui promovido com base em nossas etnografias, bem como de acordo com uma série de estudos que vêm se acumulando já há décadas nas ciências sociais brasileiras, podemos perceber a precariedade como parte de um regime jurídico de reconhecimento de uma cidadania desigual. Ou seja, a produção de desigualdade como um recurso jurídico. A princípio, esse regime jurídico reverbera na vida de sujeitos cujo reconhecimento legítimo do Estado de seus direitos é relativizado pela própria lei, de modo que a "precariedade" aparece como parte desse processamento jurídico de produção de desigualdade. Então, perceber a precariedade enquanto categoria relevante, buscando enquadrá-la como um termo dotado de sentidos mais abrangentes requer relativizar a aplicação de um direito desigual. Assim, ser precário ou ter um direito precário é como ter uma marca que dita o lugar ou os direitos que você receberá do Estado a partir do exercício da sua cidadania. Como no caso de não ter direitos trabalhistas reconhecidos a outras classes trabalhadoras para as domésticas e a consequente legitimação da ação letal do Estado sobre a vida daqueles sujeitos reconhecidos como "crias de favela".

Com isso, as pesquisas apontam como esse processo de precarização possibilita uma manutenção e controle da desigualdade por meio de instituições que regulam trajetórias de vidas. Para o presente artigo, focamos em dados que envolvem o judiciário e a polícia, já que no diálogo de nossas pesquisas percebemos que, para além da disponibilização de direitos desiguais, as moralidades que legitimam as hierarquias são fundadas em valores morais de ordem anti-republicana no seio dessas instituições. Segundo Pires (2017), a precariedade funciona como um dispositivo que cria uma suspeição sobre as pessoas e legitimam socialmente desigualdades nas relações sociais. Suspeição que não está ligada ao que se fez ou deixou de fazer, mas - como aqui demonstrado - se dá a respeito de quem se é na hierarquia social brasileira. Por isso desenvolvemos o conceito de "precariedade à brasileira", não no sentido de apontar uma peculiaridade da nossa sociedade, mas para apontar uma série de processos de suspeição que permeiam tanto a noção de precariedade da sociologia do trabalho como aquela trazida por Pires (2017).

A "precariedade à brasileira" coloca crias, domésticas e mais outros tantos segmentos da sociedade numa relação diferenciada com diferentes instâncias do Estado. Essas pessoas acessam direitos a partir de discursos que se aplicam sobre suas práticas. Então, percebemos uma suspeição, que classifica desigualmente diferentes etapas do exercício do viver (como o 
trabalho ou as experimentações da infância) a partir de estereótipos. Esses últimos, como no caso da doméstica e do cria, se aplicam como um marcador de perigo sobre aqueles que são precarizados. Assim, tais discursos que colocam as pessoas como perigosas, nos motivaram a refletir sobre as justificações para a situação de desigualdade, como descrevemos no presente artigo e que remetem à "precariedade à brasileira".

\section{REFERÊNCIAS}

1. ALBERNAZ, Elizabete. Palácios sem reis, democracias sem cidadãos: política, cotidiano e a formação de mercados da exclusão em dois contextos do "sul-global". 2019. Tese (Doutorado em Antropologia) - Programa de Pós-Graduação em Antropologia, Universidade Federal Fluminense, Niterói.

2. ANTUNES, Ricardo. Os sentidos do trabalho: ensaio sobre a afirmação e a negação do trabalho. São Paulo: Boitempo Editorial, 2015.

3. BARBOSA, Fernando Cordeiro. Trabalho e residência: estudo das ocupações de empregada doméstica e empregado de edifício a partir de migrantes "nordestinos". Niterói: EdUFF, 2000.

4. BOURDIEU, Pierre. Contrafogos: táticas para enfrentar a invasão neoliberal. Rio de Janeiro: Jorge Zahar Ed., 1998.

5. BUTLER, Judith. Vida precaria: El poder del duelo y de la violencia. Buenos Aires: Paidós, 2006.

6. CARVAlHO, José Murilo de. Cidadania no Brasil: o longo caminho. Rio de Janeiro: Civilização Brasileira, 2007.

7. CASTELLS, Manuel. A Era da informação: Economia, Sociedade e Cultura. ASociedade em Rede. Lisboa: Fundação Calouste Gulbenkian, v. 1, 2002.

8. COELHO, Maria Claudia; REZENDE, Claudia. Antropologia das Emoções. Rio de Janeiro: Editora FGV, 2013.

9. DA MATTA, Roberto. Carnavais, malandros e heróis: para uma sociologia do dilema brasileiro. Rio de Janeiro, Rocco, 1979.

10. DA MATTA, Roberto. O que faz o brasil, Brasil? Rio de Janeiro: Rocco, 1986.

11. FOUCAULT, Michel. Vigiar e punir. Petrópolis: Vozes, 1997. 
12. FREIXO, Alessandra. Verificando a procedência das informações: a Polícia Civil e os expedientes preliminares de investigação. 2015. Dissertação (Mestrado em Direito Constitucional) - Programa de Pós-Graduação em Direito Constitucional, Universidade Federal Fluminense, Niterói.

13. FREYRE, Gilberto. Sobrados e Mucambos. Rio de Janeiro: Record, 1990.

14. GARAU, Marilha. Uma análise das relações da polícia militar com os moradores de uma favela ocupada por UPP. Rev. Direito Práxis, Rio de Janeiro, v. 8, n. 3, p. 2106-2145, 2017. Disponível em: https://www.scielo.br/scielo.php?script=sci arttext\&pid=S2179-89662017000302106. Acesso em: 16 fev. 2020.

15. GOMES, Fabio Medina. Amizades muito hierárquicas: direitos e emoções nas relações entre domésticas e patroas. Cadernos de Campo, São Paulo v. 24, p. 290-314, 2015. Disponível em: https://www.revistas.usp.br/cadernosdecampo/article/view/98272. Acesso em: 02 fev. 2020.

16. GUEDES, S. L. Jogo de Corpo: Um Estudo de Construção Social de Trabalhadores. 1. ed. Niterói: EdUFF, 1997.

17. LIMA, Roberto Kant de. A Polícia na Cidade do Rio de Janeiro: seus dilemas e paradoxos. Rio de Janeiro: Ed. Forense, 1995.

18. MENDES, Regina Lúcia Teixeira. Dilemas da decisão judicial. As representações de juízes brasileiros sobre o princípio do livre convencimento motivado. 2008. Tese (Doutorado em Direito) - Universidade Gama Filho, Rio de Janeiro.

19. PIRES, Lenin. Arreglar não é pedir arrego - uma etnografia de processos de administração institucional de conflitos no âmbito da venda ambulante em Buenos Aires e Rio de Janeiro. 2010. Tese (Doutorado em Antropologia) - Programa de Pós-Graduação em Antropologia, Universidade Federal Fluminense, Niterói.

20. PIRES, Lenin. Precários e perigosos: possíveis relações entre formalidade e informalidade em processos de administração de conflitos no Rio de Janeiro. In: GLEDHILL, John; HITA, Maria Gabriela; PERELMAN, Mariano (Org.). Disputas em torno do espaço urbano: processos de produção/construção e apropriação das cidades. Salvador: EDUFBA, v. 1, 2017, p. 337-354.

21. PIRES, Lenin. Limites e Desafios de um mundo sob o signo da precariedade. Niterói: Antropolítica: Revista Contemporânea de Antropologia, v. 43, p. 283-293, 2017. Disponível em: https://periodicos.uff.br/antropolitica/article/view/41770. Acesso em: 02 fev. 2020.

22. RUSSOMANO, Mozart Victor. O empregado e o empregador no direito brasileiro. São Paulo: Forense, 1984.

23. SAFFIOTI, Heleieth I. B. Emprego doméstico e capitalismo. Petrópolis: Vozes, 1978.

24. SANTOS, Aloysio. Manual de contrato de trabalho doméstico: direitos, deveres e 
garantias dos empregados e dos empregadores domésticos. Rio de Janeiro: Forense, 2003.

25. SANTOS, Solano. “Tá tranquilo, tá favorável?" - Ordem Pública e Violência Social em uma perspectiva etnográfica. 2016. Dissertação (Mestrado em Direito Constitucional) - Programa de Pós-Graduação em Direito Constitucional, Universidade Federal Fluminense, Niterói.

26. SILVA, Gabriel Borges. "Quantos ainda vão morrer eu não sei”: o regime do arbítrio, curtição vida e morte em um lugar chamado de favela. 2019. Tese (Doutorado em Sociologia e Direito) - Programa de Pós-Graduação em Sociologia e Direito, Universidade Federal Fluminense, Niterói.

27. SILVA, Gabriel Borges. Entre precariedades e os "direitos" que delas advém: uma etnografia do Mercado Popular da Uruguaiana. 2014. Dissertação (Mestrado em Direito Constitucional) - Programa de Pós-Graduação em Direito Constitucional, Universidade Federal Fluminense, Niterói.

28. SILVA, Gabriel Borges. O Desequilíbrio que se "equilibra": Reflexões acerca do Regime de Precariedade e seu impacto na Regulação do Espaço Público. In: MELLO, Cleyson de Moraes; MARTINS, Vanderlei; PEREIRA, João Eduardo de Alves. O Direito em Movimento. Juiz de Fora: Editar, 2015, p. 261-272.

29. SILVA, Gabriel Borges. Os rituais e as formas de sociabilidade no Mercado Popular da Rua Uruguaiana: Relato de Experiência. Valença: Revista Saber Digital, v. 9, n. 2, p. 1-19, 2016. Disponível em: http://revistas.faa.edu.br/index.php/SaberDigital/article/ view/204. Acesso em: 16 fev. 2020.

30. SILVA, Gabriel Borges; FREIXO, Alessandra Soares. Camelôs, autoridades e Mercado Popular da Uruguaiana: uma análise sobre a precariedade na utilização do espaço público. In: REUNIÃO BRASILEIRA DE ANTROPOLOGIA, 29, 2014, Natal. Anais... Brasília: Editora Kiron, 2014. p. 1096.

31. SOUZA, Jessé. Gilberto Freyre e a singularidade cultural brasileira. São Paulo: Tempo social. v. 12, n. 1, p. 69-100, 2000. Disponível em: https://www.revistas.usp.br/ts/article/ view/12320. Acesso em: 02 mar. 2020.

32. SOUZA, Jessé. Classe média no espelho. Sua história, seus sonhos e ilusão, sua realidade. Rio de Janeiro: Estação Brasil, 2018.

33. TELLES, Lorena. Libertas entre sobrados: mulheres negras e trabalho doméstico em São Paulo (1880-1920). São Paulo: Alameda, 2013.

34. VIANA, Segadas, et al. Instituições de direito do trabalho. São Paulo: LTr, 1957. 
Gabriel Borges da Silva

Doutor pelo Programa de Pós-Graduação em Sociologia e Direito da Universidade Federal Fluminense. Mestre em Direito Constitucional pela Universidade Federal Fluminense. Professor substituto na Universidade Estadual do Mato Grosso. ID ORCID: https://orcid.org/0000-00017080-7676. E-mail: gabrielborgesadv@yahoo.com.br. Colaboração: pesquisa bibliográfica, pesquisa empírica, análise de dados e redação.

\section{Fábio Medina Gomes}

Doutor em Antropologia pelo Programa de Pós-Graduação em Antropologia da Universidade Federal Fluminense. Mestre em Direito pelo Programa de Pós-Graduação em Direito Constitucional, também da Universidade Federal Fluminense. Professor substituto de Direito na Universidade do Estado do Mato Grosso. ID ORCID: https://orcid.org/0000-0001-7115-8014. E-mail: fabiodemedina@gmail.com. Colaboração: pesquisa bibliográfica, pesquisa empírica, análise de dados e redação. 